\title{
The relationship between prolactin and adipose tissue and metabolic parameters in patients with polycystic ovary syndrome
}

\author{
Gültekin Adanaş Aydın ${ }^{1}$, Hilal Gülsüm Turan Özsoyْ \\ ${ }^{1}$ Department of Obstetrics and Gynecology, University of Health Sciences, Bursa Yüksek Ihtisas Training and Research Hospital, Bursa, \\ Turkey \\ ${ }^{2}$ Department of Radiology, Bursa Çekirge Hospital, Bursa, Turkey
}

\begin{abstract}
Objectives: Polycystic ovary syndrome is a reproductive endocrinopathy, predominantly accompanied by insulin resistance, obesity, and metabolic disorder. In this study, we aimed to investigate the possible relationship between prolactin and adipose tissue and metabolic parameters in patients with polycystic ovary syndrome (PCOS).
\end{abstract}

Methods: A total of 58 patients with PCOS and 34 body mass index (BMI)-matched healthy controls between September 2018 and March 2019 were included in the study. Visceral and subcutaneous adipose tissues were measured using ultrasonography. Serum prolactin, fasting blood glucose, insulin, low-density lipoprotein cholesterol (LDL-C), high-density lipoprotein cholesterol (HDL-C), triglyceride, total cholesterol, luteinizing hormone (LH), total testosterone, dehydroepiandrosterone sulfate (DHEA-S), and 17-hydroxyprogesterone (17-OHP) levels were measured.

Results: The median BMI $(p=0.001)$, waist circumference $(p=0.002)$, hip circumference $(p=0.003)$, waistto-hip ratio $(p=0.013)$, LH $(p=0.012)$, total testosterone $(p=0.004)$, DHEA-S $(p=0.049), 17-\mathrm{OHP}(p=$ $0.001)$, insulin $(p=0.001)$, minimum preperitoneal fat thickness $(\mathrm{p}=0.001)$, maximum preperitoneal fat thickness $(p=0.048)$, and intraperitoneal fat thickness $(p=0.018)$ were significantly higher in the PCOS group compared to the control group. However, there was no significant correlation between prolactin levels and adipose tissue parameters and insulin levels in the patients with PCOS.

Conclusions: Although there was an increase in the preperitoneal and intraperitoneal fat thickness in the PCOS group compared to the control group, no significant correlation was observed between prolactin and visceral and subcutaneous adipose tissues and metabolic parameters.

Keywords: Prolactin, polycystic ovary syndrome, adipose tissue

Drolactin (PRL) is a versatile hormone which plays 1 a central role in metabolic functions and tumorogenesis, as well as reproductive and immune system [1]. It is mainly produced in the pituitary gland and in extrapituitary tissues such as human endometrium, decidua, brain, breast, and adipose tissue [2]. Previous studies have shown a complex relationship between PRL and adipose tissue and PRL is implicated in the regulation of adipogenesis and function of adipocytes [2] . 
Polycystic ovary syndrome (PCOS) is a common hormonal disorder in women of reproductive age characterized by irregular menstruation, chronic anovulation, and clinic and/or biochemical hyperandrogenism with morphologically characteristic feature of polycystic ovaries [3]. Metabolic disorders are more common in these patients, compared to healthy individuals, due to insulin resistance and abdominal obesity [4].

Although the regulation of PRL release is altered in PCOS patients, the relationship between PRL and adiposity is still unclear [5]. Therefore, the relationship between PRL and increased adipose tissue and metabolic disorders still remains to be elucidated in this patient population.

In the present study, we aimed to investigate the possible relationship between PRL and adipose tissue and metabolic parameters in patients with PCOS compared to healthy controls.

\section{METHODS}

\section{Study population}

This cross-sectional study was carried out at Department of Obstetrics and Gynecology of Bursa Yüksek İhtisas Training and Research Hospital between September 2018 and March 2019. A total of 58 patients with PCOS and 34 body mass index (BMI)-matched healthy controls were included. In the patient group, the diagnosis of PCOS was made according to the Rotterdam criteria including at least two of the following three features: i) oligo/anovulation, ii) clinical and/or biochemical hyperandrogenism, and iii) polycystic ovaries on ultrasonography (USG) (6). The control group consisted of healthy individuals in whom no clinical, laboratory, or USG signs of PCOS were present. Exclusion criteria were as follows: history of diabetes, hyperprolactinemia, Cushing syndrome, congenital adrenal hyperplasia, thyroid disorders, and hypertension. Patients who received oral contraceptives, anti-androgens, aspirin, statin, and insulin-sensitizing agents within the past six months were also excluded. A written informed consent was obtained from each participant. The study protocol was approved by the Ethics Committee of Bursa Yüksek İhtisas Training and Research Hospital. (2011-KAEK-25 2018/06-31).
The study was conducted in accordance with the principles of the Declaration of Helsinki.

\section{Biochemical analyses and hormone assays}

Blood specimens were collected for biochemical and hormone analyses in the early follicular phase (between Day 2 and Day 5 of the menstrual cycle) with at least 12-h overnight fasting between 8.00 and 10.00 AM.Follicle-stimulating hormone (FSH), luteinizing hormone (LH), estradiol (E2), total testosterone, dehydroepiandrosterone sulfate (DHEA), insulin, and 17-hydroxyprogesterone (17-OHP) were analyzed using the Abbott ARCHITECT $^{\circledR}$ assay (Abbott Laboratories, Singapore). In addition, fasting blood glucose, total cholesterol, low-density lipoprotein cholesterol (LDL-C), high-density lipoprotein cholesterol (HDL-C), and triglyceride (TG) were evaluated using the Synchron LX20, Beckman Coulter Diagnostics, USA. Insulin resistance was calculated using the Homeostatic Model Assessment Insulin Resistance (HOMA-IR) formula (fasting glucose $(\mathrm{mg} / \mathrm{dL}) \times$ fasting insulin $(\mu \mathrm{U} / \mathrm{mL}) / 405)$. The model of adipose distribution (MOAD) for women was calculated using the following formula: waist circumference/[36.58+(1.89xBMI)]. The visceral adiposity index (VAI) was calculated as $\operatorname{MOADx}(\mathrm{TG} / 0.81) \times(1.52 / \mathrm{HDL})$.

\section{Anthropometric measurements}

The body weight, height, and BMI were calculated for each participant. The waist circumference was measured at the narrowest part between the lower border of the rib cage and the iliac crest, while the hip circumference was measured at the greater trochanter while standing erect. The BMI was calculated as the weight in kilogram divided by height in meters squared.

\section{Carotid intima-media thickness measurement}

The carotid intima-media thickness (CIMT) was defined as the average of the three thickness measurements between the intimal and medial-adventitial interfaces and was measured in the supine position with head flexion. The CIMT measurements were performed by an experienced radiologist.

\section{Adipose tissue measurement}

The thickness of subcutaneous, preperitoneal, 
intraperitoneal, and perirenal adipose tissues was measured using USG. The measurement was performed in the supine position in a fasting state by having the patient hold his/her breath to avoid any possible effect of respiration and abdominal wall tension. To avoid fat compression errors, the USG probe was placed above a given site without any pressure. Minimum subcutaneous and preperitoneal fat thickness were measured by longitudinal scanning with the use of (Toshiba Aplio 500, Japenese) 7 Mhz transducer from the xyphoid process, while maximum subcutaneous fat thickness was measured using the same transducer at the level of the umbilicus. Intraperitoneal fat thickness was measured by transverse scanning with the use of $5 \mathrm{Mhz}$ probe in the midline of the abdomen, 2-cm above the umbilicus. Three measures were obtained based on the intraperitoneal fat thickness measurement: the distance from the fascia of rectus abdominis muscle to the vertebral column, the distance from the peritoneum to the vertebral column, and the distance from the linea alba to the vertebral column. Perirenal fat thickness was measured from the perirenal fascia to the renal surface on a long-axis view of the right kidney.

\section{Statistical Analysis}

Statistical analysis was performed using the SPSS version 23. Descriptive data were expressed in mean \pm standard deviation (SD), median (min-max) values, and number and frequency. The Kolmogorov-Smirnov test was used to check the normality assumption. The Mann-Whitney U test was performed to compare variables between the patient and control groups. The Spearman's rank correlation analysis was used to investigate any relationship between serum PRL and other variables. After necessary adjustments for age, BMI, hip circumference, and waist-to-hip ratio were made, the partial Spearman's rank correlation analysis was performed. A multiple linear regression model was used to analyze the impact of potential variables on serum PRL levels. A $p$ value of $<0.05$ was considered statistically significant.

\section{RESULTS}

A total of 92 participants were included in this study. The study group consisted of 58 patients with
PCOS and the control group consisted of 34 healthy individuals. However, as not every participant underwent all tests, the number of participants in both patient group and control group varied. The mean age was $27.07 \pm 4.88$ years in the patient group and 28.58 \pm 4.78 in the control group, indicating no significant difference between the groups. Baseline demographic and clinical characteristics of the study population are shown in Table 1.

The median body weight ( $p=0.004)$, BMI $(p=$ $0.001)$, Ferriman-Gallwey Hirsutism (FGH) scores ( $p$ $=0.001)$, waist circumference $(p=0.002)$, hip circumference $(\mathrm{p}=0.003)$, waist-to-hip ratio $(\mathrm{p}=0.013), \mathrm{LH}$ $(p=0.012)$, total testosterone $(p=0.004)$, DHEA-S $(p$ $=0.049), 17-\mathrm{OHP}(p=0.001)$, insulin $(p=0.001)$, CIMT, minimum preperitoneal fat thickness $(p=$ $0.001)$, maximum preperitoneal fat thickness $(p=$ $0.048)$, and intraperitoneal fat thickness $(p=0.018)$ were significantly higher in the PCOS group compared to the control group. There was no significant difference in other variables between the groups.

Table 2 shows monotonic relationship between serum PRL and other variables. There was no significant correlation between serum PRL and any of the variables in the control group, while serum PRL significantly decreased with increasing age in the PCOS group ( $p=0.001)$. However, there was no significant linear correlation between serum PRL and other variables in the PCOS group.

After necessary adjustments for age, BMI, hip circumference, and waist-to-hip ratio were made, correlation analysis was repeated. A positive and significant correlation was found between serum PRL levels and FGH scores $(p=0.025)$, TG levels ( $p=$ $0.020)$, and mid CIMT $(p=0.039)$ in the control group, while no significant correlation was found in the PCOS group (Table 3).

A multiple linear regression model was used to analyze the impact of potential variables on serum PRL levels. In the PCOS group, there was a significant correlation between age $(p=0.020)$, waist-to-hip ratio $(p=0.044)$, and HDL-C $(p=0.049)$ (Table 4$)$.

\section{DISCUSSION}

Polycystic ovary syndrome is a reproductive endocrinopathy, predominantly accompanied by 


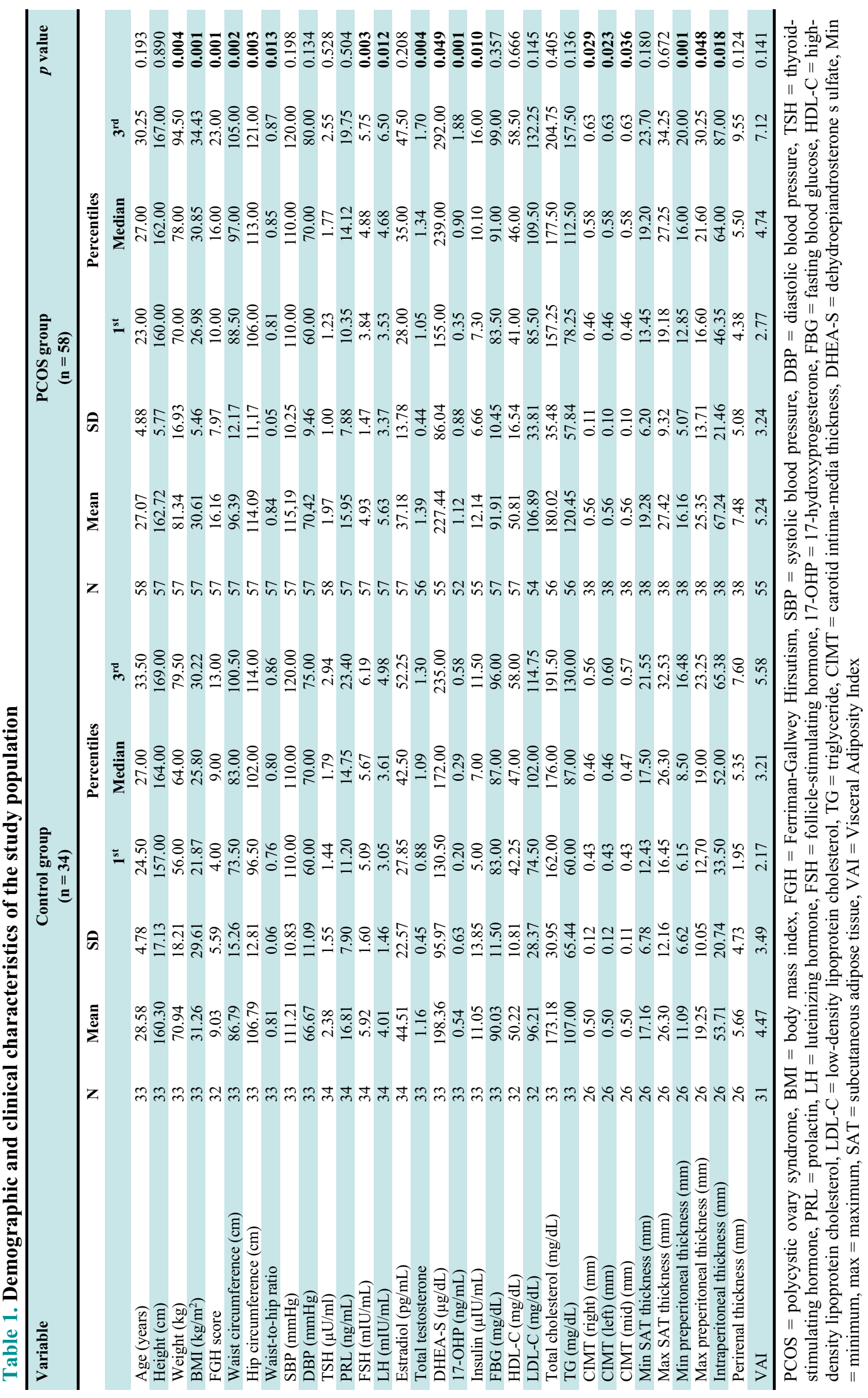


Table 2. Monotonic relationship between serum prolactin and other variables

\begin{tabular}{|c|c|c|c|c|c|c|}
\hline \multirow{3}{*}{ Variable } & \multicolumn{6}{|c|}{ Serum PRL level } \\
\hline & \multicolumn{3}{|c|}{$\begin{array}{l}\text { Control group } \\
\quad(\mathbf{n}=\mathbf{3 4})\end{array}$} & \multicolumn{3}{|c|}{$\begin{array}{c}\text { PCOS group } \\
\quad(n=58)\end{array}$} \\
\hline & $r$ & p value & $\mathbf{N}$ & $r$ & p value & $\mathbf{N}$ \\
\hline Age (years) & 0.016 & 0.928 & 33 & -0.525 & 0.001 & 57 \\
\hline Height (cm) & -0.159 & 0.376 & 33 & 0.121 & 0.375 & 56 \\
\hline Weight (kg) & -0.325 & 0.065 & 33 & -0.090 & 0.512 & 56 \\
\hline BMI $\left(\mathrm{kg} / \mathrm{m}^{2}\right)$ & -0.272 & 0.126 & 33 & -0.108 & 0.429 & 56 \\
\hline FGH score & 0.231 & 0.203 & 32 & 0.111 & 0.414 & 56 \\
\hline Waist circumference $(\mathrm{cm})$ & -0.206 & 0.249 & 33 & -0.047 & 0.730 & 56 \\
\hline Hip circumference (cm) & -0.221 & 0.216 & 33 & -0.053 & 0.696 & 56 \\
\hline Waist-to-hip ratio & -0.046 & 0.798 & 33 & -0.008 & 0.951 & 56 \\
\hline SBP (mmHg) & 0.055 & 0.762 & 33 & -0.050 & 0.715 & 56 \\
\hline DBP (mmHg) & -0.001 & 0.993 & 33 & 0.027 & 0.842 & 56 \\
\hline $\mathrm{TSH}(\mu \mathrm{U} / \mathrm{ml})$ & -0.039 & 0.825 & 34 & 0.191 & 0.154 & 57 \\
\hline FSH (mIU/mL) & -0.123 & 0.487 & 34 & -0.010 & 0.940 & 57 \\
\hline LH (mIU/mL) & 0.152 & 0.390 & 34 & -0.108 & 0.425 & 57 \\
\hline Estradiol (pg/mL) & 0.180 & 0.308 & 34 & -0.061 & 0.655 & 57 \\
\hline Total testosterone & -0.061 & 0.735 & 33 & 0.019 & 0.890 & 56 \\
\hline DHEA-S $(\mu \mathrm{g} / \mathrm{dL})$ & -0.167 & 0.352 & 33 & 0.166 & 0.229 & 54 \\
\hline 17-OHP (ng/mL) & 0.242 & 0.174 & 33 & 0.216 & 0.124 & 52 \\
\hline Insulin $(\mu \mathrm{IU} / \mathrm{mL})$ & 0.055 & 0.763 & 33 & -0.070 & 0.614 & 55 \\
\hline FBG $(\mathrm{mg} / \mathrm{dL})$ & -0.209 & 0.244 & 33 & -0.152 & 0.258 & 57 \\
\hline HDL-C (mg/dL) & 0.196 & 0.284 & 32 & 0.134 & 0.319 & 57 \\
\hline LDL-C (mg/dL) & -0.166 & 0.364 & 32 & -0.022 & 0.873 & 54 \\
\hline Total cholesterol (mg/dL) & 0.060 & 0.742 & 33 & -0.073 & 0.93 & 56 \\
\hline $\mathrm{TG}(\mathrm{mg} / \mathrm{dL})$ & 0.239 & 0.181 & 33 & -0.153 & 0.261 & 56 \\
\hline CIMT (right) (mm) & 0.246 & 0.246 & 24 & 0.022 & 0.97 & 36 \\
\hline CIMT (left) (mm) & -0.085 & 0.693 & 24 & -0.011 & 0.951 & 36 \\
\hline CIMT (mid) (mm) & 0.079 & 0.715 & 24 & 0.007 & 0.966 & 36 \\
\hline Min SAT thickness (mm) & -0.042 & 0.844 & 24 & 0.252 & 0.37 & 36 \\
\hline Max SAT thickness (mm) & -0.211 & 0.322 & 24 & 0.042 & 0.809 & 36 \\
\hline $\begin{array}{l}\text { Min preperitoneal thickness } \\
(\mathrm{mm})\end{array}$ & -0.044 & 0.837 & 24 & 0.228 & 0.182 & 36 \\
\hline $\begin{array}{l}\text { Max preperitoneal thickness } \\
(\mathrm{mm})\end{array}$ & -0.226 & 0.288 & 24 & 0.058 & 0.735 & 36 \\
\hline Intraperitoneal thickness (mm) & -0.156 & 0.468 & 24 & 0.205 & 0.230 & 36 \\
\hline Perirenal thickness (mm) & -0.237 & 0.264 & 24 & 0.050 & 0.772 & 36 \\
\hline VAI & 0.106 & 0.569 & 31 & -0.077 & 0.578 & 55 \\
\hline
\end{tabular}

PCOS = polycystic ovary syndrome, BMI = body mass index, FGH = Ferriman-Gallwey Hirsutism, SBP = systolic blood pressure, DBP = diastolic blood pressure, $\mathrm{TSH}=$ thyroid-stimulating hormone, $\mathrm{PRL}=$ prolactin, $\mathrm{LH}=$ luteinizing hormone, $\mathrm{FSH}=$ follicle-stimulating hormone, 17-OHP = 17-hydroxyprogesterone, $\mathrm{FBG}=$ fasting blood glucose, HDL-C = high-density lipoprotein cholesterol, LDL-C = low-density lipoprotein cholesterol, $\mathrm{TG}=$ triglyceride, $\mathrm{CIMT}=$ carotid intima-media thickness, DHEA-S $=$ dehydroepiandrosterone sulfate, Min $=$ minimum, $\max =$ maximum, SAT $=$ subcutaneous adipose tissue, $\mathrm{VAI}=$ Visceral Adiposity Index 
Table 3. Corrected correlation analysis with adjusted variables

\begin{tabular}{|c|c|c|c|c|c|}
\hline \multirow[t]{3}{*}{ Variable } & & \multicolumn{2}{|c|}{$\begin{array}{l}\text { Control group } \\
\quad(n=34)\end{array}$} & \multicolumn{2}{|c|}{$\begin{array}{l}\text { PCOS group } \\
(n=58)\end{array}$} \\
\hline & & \multicolumn{2}{|c|}{ Serum PRL level } & \multicolumn{2}{|c|}{ Serum PRL level } \\
\hline & & $r$ & $p$ value & $r$ & $p$ value \\
\hline \multirow{26}{*}{$\begin{array}{l}\text { BMI \& waist-to-hip } \\
\text { ratio }\end{array}$} & FGH score & 0.499 & 0.025 & 0.210 & 0.302 \\
\hline & $\mathrm{SBP}(\mathrm{mmHg})$ & 0.144 & 0.545 & 0.076 & 0.711 \\
\hline & $\mathrm{DBP}(\mathrm{mmHg})$ & -0.114 & 0.631 & 0.099 & 0.631 \\
\hline & $\mathrm{TSH}(\mu \mathrm{U} / \mathrm{ml})$ & 0.186 & 0.433 & -0.218 & 0.285 \\
\hline & FSH (mIU/mL) & -0.136 & 0.569 & -0.011 & 0.958 \\
\hline & LH (mIU/mL) & -0.020 & 0.933 & -0.148 & 0.471 \\
\hline & Estradiol (pg/mL) & 0.328 & 0.158 & -0.026 & 0.901 \\
\hline & Total testosterone & 0.268 & 0.253 & -0.023 & 0.911 \\
\hline & DHEA-S $(\mu \mathrm{g} / \mathrm{dL})$ & 0.219 & 0.353 & -0.124 & 0.545 \\
\hline & 17-OHP (ng/mL) & 0.174 & 0.464 & -0.014 & 0.947 \\
\hline & Insulin $(\mu \mathrm{IU} / \mathrm{mL})$ & 0.297 & 0.204 & 0.099 & 0.629 \\
\hline & FBG (mg/dL) & -0.098 & 0.682 & -0.193 & 0.344 \\
\hline & HDL-C (mg/dL) & 0.354 & 0.126 & 0.203 & 0.319 \\
\hline & LDL-C (mg/dL) & -0.001 & 0.997 & -0.078 & 0.706 \\
\hline & Total cholesterol (mg/dL) & 0.182 & 0.442 & -0.041 & 0.841 \\
\hline & $\mathrm{TG}(\mathrm{mg} / \mathrm{dL})$ & 0.516 & 0.020 & -0.164 & 0.423 \\
\hline & CIMT_SAG & 0.599 & 0.005 & -0.181 & 0.377 \\
\hline & CIMT_SOL & 0.296 & 0.205 & -0.245 & 0.228 \\
\hline & CIMT_ORT & 0.465 & 0.039 & -0.224 & 0.271 \\
\hline & Min SAT thickness (mm) & 0.108 & 0.651 & 0.190 & 0.351 \\
\hline & Max SAT thickness (mm) & -0.085 & 0.723 & 0.005 & 0.981 \\
\hline & $\begin{array}{l}\text { Min preperitoneal thickness } \\
(\mathrm{mm})\end{array}$ & 0.188 & 0.427 & 0.087 & 0.671 \\
\hline & $\begin{array}{l}\text { Max preperitoneal thickness } \\
(\mathrm{mm})\end{array}$ & -0.071 & 0.767 & -0.001 & 0.995 \\
\hline & Intraperitoneal thickness (mm) & 0.002 & 0.994 & 0.245 & 0.228 \\
\hline & Perirenal thickness (mm) & -0.132 & 0.580 & 0.035 & 0.865 \\
\hline & VAI & 0.387 & 0.092 & -0.175 & 0.392 \\
\hline
\end{tabular}

PCOS = polycystic ovary syndrome, $\mathrm{BMI}=$ body mass index, $\mathrm{FGH}=$ Ferriman-Gallwey Hirsutism, $\mathrm{SBP}=$ systolic blood pressure, $\mathrm{DBP}=$ diastolic blood pressure, $\mathrm{TSH}=$ thyroid-stimulating hormone, $\mathrm{PRL}=$ prolactin, $\mathrm{LH}=$ luteinizing hormone, $\mathrm{FSH}=$ follicle-stimulating hormone, 17-OHP $=17$-hydroxyprogesterone, $\mathrm{FBG}=$ fasting blood glucose, HDL-C $=$ high-density lipoprotein cholesterol, LDL-C $=$ low-density lipoprotein cholesterol, $\mathrm{TG}=$ triglyceride, $\mathrm{CIMT}=$ carotid intima-media thickness, DHEA-S $=$ dehydroepiandrosterone sulfate, Min $=$ minimum, $\max =$ maximum, $\mathrm{SAT}=$ subcutaneous adipose tissue, $\mathrm{VAI}=$ Visceral Adiposity Index 
Table 4. Multiple linear regression analysis

\begin{tabular}{|c|c|c|c|c|c|c|}
\hline \multirow[t]{2}{*}{ Group } & & \multicolumn{2}{|c|}{$\begin{array}{l}\text { Unstandardized } \\
\text { Coefficients }\end{array}$} & \multirow{2}{*}{$\begin{array}{c}\begin{array}{c}\text { Standardized } \\
\text { Coefficients }\end{array} \\
\beta \beta\end{array}$} & \multirow[t]{2}{*}{$t$} & \multirow[t]{2}{*}{ p value } \\
\hline & & $\beta$ & SE & & & \\
\hline \multirow[t]{22}{*}{ PCOS } & Age (years) & -1.362 & 0.529 & -0.885 & -2.572 & 0.020 \\
\hline & BMI $\left(\mathrm{kg} / \mathrm{m}^{2}\right)$ & 0.384 & 0.807 & 0.282 & 0.476 & 0.640 \\
\hline & FGH score & -0.231 & 0.275 & -0.239 & -0.839 & 0.413 \\
\hline & Waist-to-hip ratio & 107.688 & 49.518 & 0.812 & 2.175 & 0.044 \\
\hline & SBP (mmHg) & -0.003 & 0.236 & -0.004 & -0.014 & 0.989 \\
\hline & DBP (mmHg) & 0.037 & 0.238 & 0.048 & 0.156 & 0.878 \\
\hline & TSH $(\mu \mathrm{U} / \mathrm{ml})$ & 0.268 & 1.821 & 0.045 & 0.147 & 0.885 \\
\hline & FSH (mIU/mL) & -0.443 & 1.668 & -0.087 & -0.266 & 0.794 \\
\hline & $\mathrm{LH}(\mathrm{mIU} / \mathrm{mL})$ & -0.894 & 0.720 & -0.322 & $-1,243$ & 0.231 \\
\hline & Estradiol (pg/mL) & 0.155 & 0.110 & 0.383 & 1.411 & 0.176 \\
\hline & Total testosterone & -3.806 & 5.265 & -0.182 & -0.723 & 0.480 \\
\hline & DHEA-S $(\mu \mathrm{g} / \mathrm{dL})$ & -0.012 & 0.026 & -0.121 & -0.467 & 0.647 \\
\hline & 17-OHP (ng/mL) & -0.322 & 4.116 & -0.030 & $-0,078$ & 0.939 \\
\hline & Insulin $(\mu \mathrm{IU} / \mathrm{mL})$ & 0.125 & 0.197 & 0.190 & 0.635 & 0.534 \\
\hline & HDL-C (mg/dL) & 0.488 & 0.233 & 0.731 & 2.000 & 0.049 \\
\hline & TG (mg/dL) & -0.059 & 0.139 & -0.384 & -0423 & 0.677 \\
\hline & CIMT (mid) (mm) & 6.249 & 25.749 & 0.083 & 0.243 & 0.811 \\
\hline & Min SAT thickness (mm) & 0.462 & 0.605 & 0.399 & 0.764 & 0.455 \\
\hline & Max SAT thickness (mm) & -0.260 & 0.377 & -0.333 & -0.689 & 0.500 \\
\hline & Max preperitoneal thickness (mm) & -0.181 & 0.193 & -0.330 & -0.938 & 0.362 \\
\hline & Intraperitoneal thickness (mm) & -0.112 & 0.172 & -0.321 & -0.654 & 0.522 \\
\hline & Perirenal thickness (mm) & 0.246 & 0.631 & 0.166 & 0.390 & 0.701 \\
\hline
\end{tabular}

PCOS = polycystic ovary syndrome, $\mathrm{BMI}=$ body mass index, $\mathrm{FGH}=$ Ferriman-Gallwey Hirsutism, $\mathrm{SBP}=$ systolic blood pressure, DBP = diastolic blood pressure, $\mathrm{TSH}=$ thyroid-stimulating hormone, $\mathrm{LH}=$ luteinizing hormone, $\mathrm{FSH}=$ follicle-stimulating hormone, $17-\mathrm{OHP}=17$-hydroxyprogesterone, HDL-C $=$ high-density lipoprotein cholesterol, $\mathrm{TG}=$ triglyceride, $\mathrm{CIMT}=$ carotid intima-media thickness, DHEA-S $=$ dehydroepiandrosterone sulfate, $\mathrm{Min}=$ minimu, $\max =$ maximum, $\mathrm{SAT}=$ subcutaneous adipose tissue

insulin resistance, obesity, and metabolic disorder [3]. Nearly 30 to $50 \%$ of lean patients with PCOS and those with obesity have insulin resistance and lipid metabolism disorders,suggesting that obesity is not the sole driver of metabolic alterations [7]. Several studies have demonstrated that metabolic disorders are more frequently associated with the distribution of adipose tissue rather than absolute amount of the body fat [8]. In the literature, some authors have reported no significant difference in the body composition and fat distribution between lean patients with PCOS and healthy controls [9], while some others have shown that PCOS patients have more visceral fat ratio proportionally to total body fat, suggesting a relationship between PCOS and glucose intolerance, type 2 diabetes, hypertension, and hyperlipidemia [10, 11]. Furthermore, although there are studies showing an increase in the subcutaneous adipose tissue in PCOS patients [12], some authors have not demonstrated such an increase [13]. Similarly,there are some studies showing an increase in the visceral adipose tissue [10, 14], whle some others have found no increase [13]. In 
a study, Jena et al. [15] found increased subcutaneous adipose tissue in patients with PCOS and obesity, compared to BMI-matched healthy controls. However, in the aforementioned study, there was no significant difference in the subcutaneous adipose tissue between lean PCOS patients and controls. In addition, the authors reported increased visceral adipose tissue in PCOS patients with and without obesity compared to healthy controls [15]. In another study evaluating subcutaneous, preperitoneal, intraperitoneal, mesenteric, epicardial, and perirenal adipose tissue through USG, a significant increase in the visceral adipose tissue, particularly mesenteric and intraperitoneal, was observed in patients with PCOS with and without obesity, compared to the control group [16]. In our study, although we found no significant difference in the subcutaneous fat thickness between the groups, we observed a significant increase in the preperitoneal and intraperitoneal fat thickness in the patients with PCOS.

Visceral adipose tissue is a more active driver of metabolic alterations than subcutaneous adipose tissue and is more resistant to anti-lipolytic effects of insulin, thereby, increasing abnormal lipid production and insulin resistance [17]. Although preperitoneal adipose tissue is not a part of visceral adipose tissue, it has similar properties to visceral adipose tissue, as it is anatomically located close to peritoneal, omental, and retroperitoneal adipose tissues [18].

It has been well-established that PRL plays a central role in the reproductive system. In recent years, there are also several reports suggesting that PRL can be used as a useful biomarker for metabolic syndrome, diabetes mellitus, cardiovascular and all-cause mortality $[19,20]$. It has been proposed that PRL exerts its effects on adipose tissue development and functions and pancreatic $\beta$ cells [21]. There is a complex relationship between PRL and adipose tissue: PRL has not only an effect on adipogenesis and adipocyte functions, but also is produced in adipose tissues [2]. However, the effect of PRL on systemic circulation has not been clearly understood, yet. Some authors have suggested that PRL released by the adipose tissue shows an autocrine/paracrine effect [22].

In the literature, there are several reports showing a positive or negative or no correlation between the amount of adipose tissues and PRL levels [23-25]. The discrepancy among the studies can be attributed to the type of adipose tissue examined. In a study, Kok et al. [26] found a higher rate of basal and pulsatile PRL release in premenopausal women with visceral obesity, compared to lean controls. In another study, patients with obesity had a lower PRL release from subcutaneous adipose tissue, compared to visceral adipose tissue, indicating an inverse relationship between PRL release from subcutaneous adipose tissue and BMI [2] . On the other hand, the rate of PRL released from subcutaneous and visceral adipose tissues was similar in patients without obesity. Unlike this study, we found no significant relationship between PRL levels and subcutaneous and visceral adipose tissue in our study population. Similarly, in their study, Ernst et al. [25] found no significant difference in the serum basal PRL levels one year after gastric bypass in patients with obesity, compared to baseline, despite severe weight loss.

Adipose tissue dysfunction is considered an important contributor to obesity-related metabolic disorders. In patients with obesity, excessive fat deposition leads to insulin resistance, impaired adipogenesis, altered adipokine secretion, increased inflammation and fibrosis, and reduced angiogenesis [27]. Therefore, adipose tissue modeling is critical to prevent insulin resistance and associated metabolic disorders [28]. A healthy expansion of the adipose tissue is of utmost importance to maintain insulin sensitivity, while PRL is involved in the healthy expansion of the adipose tissue and maintenance of insulin sensitivity $[19,29]$.

On the other hand, PRL may have adverse metabolic effects in patients with high serum PRL levels due to prolactinoma or the use of antipsychotics, leading to type 2 diabetes(30). Bromocriptine, a dopamine agonist, inhibits PRL levels and increase insulin sensitivity and has been used in the treatment of type 2 diabetes in recent years [31]. However, there are several studies showing no direct correlation between corrected BMI and metabolic parameters and reduced PRL levels [32].

Review of the literature reveals controversial results regarding the relationship between serum PRL levels and metabolic parameters. Some authors reported an inverse correlation between PRL levels and diabetes, metabolic syndrome, HOMA-IR, and impaired lipid metabolism $[19,33]$, while some others found a positive correlation between PRL levels and 
hypertension, insulin resistance, and aortic stiffness $[20,34,35]$. In a study, high physiological concentrations of PRL increased adiponectin release, showing a protective effect against metabolic dysfunction [28]. In another study, Albu et al. [5] found a positive correlation between adiponectin and PRL levels in patients with PCOS. In this study, VAI, but not adiponectin, was found to be a useful marker for predicting serum PRL levels. In our study, we found no significant correlation between serum PRL levels and metabolic parameters. Of note, we were unable to examine adipokine levels for adipose tissue dysfunction, although we used VAI. However, we found no significant correlation between serum PRL levels and VAI.

\section{Limitations}

Nonetheless, there are some limitations to this study. First, the study has a relatively small sample size. Second, only PCOS patients with obesity and BMI-matched healthy controls were included in this study and lean PCOS patients were unable to be evaluated. Third, thickness measurements of adipose tissues were made using USG. Finally, computed tomography and magnetic resonance imaging are more useful in the evaluation of subcutaneous and visceral adipose tissues(36), the outcomes of both methods are similar to USG $[37,38]$. In our study, we used USG as it is an inexpensive, non-invasive imaging method in our study.

\section{CONCLUSION}

In conclusion, although there was an increase in the preperitoneal and intraperitoneal fat thickness in the PCOS group compared to the control group, no significant correlation was observed between PRL levels and visceral and subcutaneous adipose tissues. In addition, we found no significant correlation between serum PRL and metabolic parameters. We, therefore, recommend further large-scale studies to establish a definite conclusion on this topic.

\section{Authors' contribution}

GAA = designed the study, searched the literature, planned the concept, made statistical analysis, prepared and edited the manuscript, reviewed the manuscript and copy-edited the text and made contributions to improve the quality of the study. HGTÖ = designed the study, searched the literature, planned the concept, made statistical analysis, prepared and edited the manuscript.

\section{Conflict of interest}

The authors disclosed no conflict of interest during the preparation or publication of this manuscript.

\section{Financing}

The authors disclosed that they did not receive any grant during conduction or writing of this study.

\section{REFERENCES}

1. Goffin V, Binart N, Touraine P, Kelly PA. Prolactin: the new biology of an old hormone. Annu Rev Physiol 2002;64:47-67. 2. Hugo ER, Borcherding DC, Gersin KS, Loftus J, BenJonathan N. Prolactin release by adipose explants, primary adipocytes, and LS14 adipocytes. J Clin Endocrinol Metab 2008;93:4006-12.

3. Norman RJ, Dewailly D, Legro RS, Hickey TE. Polycystic ovary syndrome. Lancet 2007;370: 685-97.

4. Escobar-Morreale HF, San Millan JL. Abdominal adiposity and the polycystic ovary syndrome. Trends Endocrinol Metab 2007; 18:266-72.

5. Albu A, Florea S, Fica S. Is prolactin the missing link in adipose tissue dysfunction of polycystic ovary syndrome patients? Endocrine 2016;51:163-73.

6. Rotterdam ESHRE/ASRM-Sponsored PCOS Consensus Workshop Group. Revised 2003 consensus on diagnostic criteria and long-term health risks related to polycystic ovary syndrome (PCOS). Hum Reprod 2004;19:41-7.

7. Yildrim B, Sabir N, Kaleli B. Relationship of intra-abdominal fat distribution to metabolic disorders in nonobese patients with polycystic ovary syndrome. Fertil Steril 2003;79:1358-64.

8. Kalkhoff RK, Hartz AH, Rupley D, Kissebah AH, Kelber S. Relationship of body fat distribution to blood pressure,carbohydrate tolerance, and plasma lipids in healthy obese women. J Lab Clin Med 1983;102:621-7.

9. Good C, Tulchinsky M, Mauger D, Demers LM, Legro RS.Bone density and body composition in lean women with polycystic ovary syndrome. Fertil Steril 1999;72:21-5.

10. Battaglia C, Battaglia B, Mancini F, Paradisi R, Fabbri R, Venturoli $\mathrm{S}$, et al. Ultrasonographic extended-view technique for evaluation of abdominal fat distribution in lean women with polycystic ovary syndrome. Acta Obstet Gynecol Scand 2011;90:600-8

11. Goodpaster BH, Krishnaswami S, Harris TB, Katsiaras A, Kritchevsky SB, Simonsick EM, et al. Obesity, regional body fat distribution, and the metabolic syndrome in older men and women. Arch Intern Med 2005; 165:777-83. 
12. Karabulut A, Yaylali GF, Demirlenk S, Sevket O, Acun A. Evaluation of body fat distribution in PCOS and its association with carotid atherosclerosis and insulin resistance. Gynecol Endocrinol 2012;28:111-4.

13. Mannerås-Holm L, Leonhardt H, Kullberg J, Jennische E, Odén A,Holm G, et al. Adipose tissue has aberrant morphology and function in PCOS: Enlarged adipocytes and low serum adiponectin, but not circulating sex steroids, are strongly associated with insulin resistance. J Clin Endocrinol Metab 2011;96:E304-11.

14. Cascella T, Palomba S, De Sio I, Manguso F, Giallauria F, De Simone B, et al. Visceral fat is associated with cardiovascular risk in women with polycystic ovary syndrome. Hum Reprod 2008;23:153-9.

15. Jena D, Choudhury AK, Mangaraj S, Singh M, Mohanty BK, Baliarsinha AK. Study of visceral and subcutaneous abdominal fat thickness and its correlation with cardiometabolic risk factors and hormonal parameters in polycystic ovary syndrome. Indian J Endocrinol Metab 2018;22:321-7.

16. Borruel S, Fernández-Durán E, Alpañés M, Martí D, AlvarezBlasco F, Luque-Ramírez M, et al. Global adiposity and thickness of intraperitoneal and mesenteric adipose tissue depots are increased inwomen with polycystic ovary syndrome (PCOS). J Clin Endocrinol Metab 2013;98:1254-63.

17. Liu KH, Chan YL, Chan WB, KongWL, Kong MO, Chan JCN. Sonographic measurement of mesenteric fat thickness is a good correlate with cardiovascular risk factors: comparison with subcutaneous and preperitoneal fat thickness, magnetic resonance imaging and anthropometric indexes. Int J Obes Relat Metab Disord 2003;27:1267-73.

18. Abe T, Kawakami Y, Sugita M, Yoshikawa K, Fukunaga T. Use of B-mode ultrasound for visceral fat mass evaluation:comparisons with magnetic resonance imaging. Appl Human Sci 1995; 14:133-9.

19. Balbach L, Wallaschofski H, Volzke H, Nauck M, Dorr M, Haring R. Serum prolactin concentrations as risk factor of metabolic syndromeor type 2 diabetes? BMC Endocr Disord 2013;13:12.

20. Haring R, Friedrich N, Volzke H, Vasan RS, Felix SB, Dorr $\mathrm{M}$, et al. Positive association of serum prolactin concentrations with all-cause and cardiovascular mortality. Eur. Heart J 2012;35:1215-21.

21. Freemark M, Avril I, Fleenor D, Driscoll P, Petro A, Opara E, et al. Targeted deletion of the PRL receptor: effects on islet development,insulin production, and glucose tolerance. Endocrinology 2002; 143:1378-85.

22. Ben-Jonathan N, Hugo ER, Brandebourg TD, LaPensee CR. Focus on prolactin as a metabolic hormone. Trends Endocrinol Metab 2006;17:110-16.

23. Roelfsema F, Pijl H, Keenan DM, Veldhuis JD. Prolactin secretion in healthy adults is determined by gender, age and body mass index. PLoS ONE 2012;7:e31305.

24. Chirico V, Cannavo S, Lacquaniti A, Salpietro V, Mandolfino M, Romeo PD, et al. Prolactin in obese children: a bridge between inflammation andmetabolic-endocrine dysfunction. Clin Endocrinol (Oxf) 2013;79:537-44.

25. Ernst B, Thurnheer M, Schultes B. Basal serum prolactin levels in obesity-unrelated to parameters of the metabolic syndrome and unchanged after massive weight loss. Obes Surg 2009;19:1159-62.

26. Kok P, Roelfsema F, Frolich M, Meinders AE, Pijl H. Prolactin release is enhanced in proportion to excess visceral fat in obese women. J Clin Endocrinol Metab 2004;89:4445-9.

27. Gustafson B, Hedjazifar S, Gogg S, Hammarstedt A, Smith U. Insulin resistance and impaired adipogenesis. Trends Endocrinol Metab 2015;26:193-200.

28. Ruiz-Herrera X, de Los Ríos EA, Díaz JM, Lerma-Alvarado RM, Martínez de la Escalera L, López-Barrera F, et al. Prolactin promotes adipose tissue fitness and insulinsensitivity in obese males. Endocrinology 2017;158:56-68.

29. Wagner R, Heni M, Linder K, Ketterer C, Peter A, Bohm A, et al. Age-dependentassociation of serum prolactin with glycaemia and insulinsensitivity in humans. Acta Diabetol 2014;51:71-8.

30. Berinder K, Nystroł̀m T, HoÈybye C, Hall K, Hulting AL. Insulin sensitivity and lipid profile in prolactinoma patients before and after normalization of prolactin by dopamine agonist therapy. Pituitary 2011;14:199-207.

31. Lamos EM, Levitt DL, Munir KM. A review of dopamine agonist therapy in type 2 diabetes and effects on cardio-metabolic parameters. Prim Care Diabetes 2016;10:60-5.

32. dos Santos Silva CM, Barbosa FR, Lima GA, Warszawski L, Fontes R, Domingues RC, et al. BMI and metabolic profile in patientswith prolactinoma before and after treatment with dopamineagonists. Obesity (Silver Spring) 2011;19:800-5.

33. Glintborg D, Altinok M, Mumm H, Buch K, Ravn P, Andersen M. Prolactin is associated with metabolic risk and cortisol in 1007 women with polycystic ovary syndrome. Hum Reprod 2014;29:1773-9.

34. Zhang L, Curhan GC, Forman JP. Plasma prolactin level and risk of incident hypertension in postmenopausal women. J Hypertens 2010;28:1400-5.

35. Daimon M, Kamba A, Murakami H, Mizushiri S, Osonoi S, Yamaichi M, et al. Association between serum prolactin levels and insulin resistance in non-diabetic men. PLoS One 2017; 12:e0175204.

36. Seidell JC, Bakker CJ, Van Der Kooy K. Imaging techniques for measuring adipose-tissue distribution- a comparison between computed tomography and 1.5-T magnetic resonance. Am J Clin Nutr 1990;51:953-7.

37. Leite CC, Wajchenberg BL, Radominski R, Matsuda D, Cerri GG, Halpern A, et al. Intra-abdominal thickness by ultrasonography to predict risk factors for cardiovascular disease and its correlation with anthropometric measurements. Metabolism 2002;51:1034-40.

38. Wajchenberg BL. Subcutaneous and visceral adipose tissue: their relation to the metabolic syndrome. Endocr Rev 2000;21:697-738. 